\section{MIGRAGÕES, DIÁSPORAS ÉTNICAS E POLÍTICAS LINGUÍSTICAS NOS PROCESSOS POLÍTICOS DA FEDERAĢ̃̃o RUSSA}

\author{
Magomed A. Omarov
}

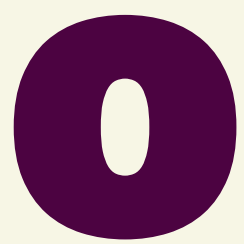

problema da adaptação e integração dos migrantes na sociedade anfitriá, bem como o papel das diásporas étnicas nos processos políticos dos países, estão se tornando uma das questôes prementes da agenda política moderna, não apenas na Rússia, mas também no resto do mundo. Faz pouco tempo que os pesquisadores da Rússia começaram a tratar do problema da migração e da formação de diásporas étnicas no quadro da moderna ciência política. Na verdade, esse problema foi se tornando cada vez mais agudo desde o início dos anos 1990, após o colapso da União Soviética e o aparecimento das formações estatais pós-soviéticas.

A situação socioeconômica e política deteriorou-se acentuadamente nas antigas repúblicas soviéticas após 1990 e não havia, no período, procedimentos e regras claras na política de migração. Em função dessas duas razões teve início uma migração descontrolada e milhōes de pessoas logo se encontraram em condiçōes incomuns, como "não-cidadãos" - como ocorreu nos Estados bálticos —, e muitos cidadãos russos e de língua do antigo país grande e unido se encontraram em um ambiente hostil, o que os forçou a mudar de local de residência e todo o seu habitat. As "diásporas do cataclismo" apareceram então como comunidades étnicas, como resultado da desintegração das grandes formações estatais e das mudanças nas fronteiras políticas, como afirma R. Brubaker [1], professor da Universidade da Califórnia.

Começaram a surgir trabalhos sobre vários aspectos da migração: sobre as possibilidades de adaptação e integração das comunidades diaspóricas, sobre o funcionamento e o desenvolvimento das diásporas étnicas nos processos políticos modernos e sobre o seu papel na política interna e externa do Estado. Na verdade, a migração de uma região para outra sempre existiu, mas não em tão larga escala, como observamos nas últimas décadas.

Nos tempos modernos, quaisquer grandes movimentos de pessoas associadas à passagem de fronteiras estatais e às migrações ao redor do mundo que caracterizam o mundo globalizado moderno estão sendo cada vez mais considerados no contexto dos problemas dos grupos étnicos e da etnicidade e sua posterior transformação em diásporas e da diasporização (integração, assimilação, adaptação etc.). Naturalmente, nem todo grupo étnico se torna uma comunidade poderosa e organizada da diáspora, capaz de exercer influência nos processos políticos, tanto no país anfitrião quanto nos países de origem.
Não trataremos especificamente das chamadas "diásporas internas", ou seja, diásporas étnicas constituídas por representantes de certos grupos étnicos que já são cidadãos do país, pois esse é um tópico bastante controverso, tanto na comunidade científica quanto nos círculos políticos e de especialistas. Ainda assim não deixamos de reconhecer o fato incontestável de que na diáspora da Ossétia ou do Daguestão, bem como de outras comunidades étnicas, como são frequentemente chamadas, ainda que constituídas por cidadãos do próprio país, líderes e membros comuns das respectivas associaçôes culturais nacionais não se sintam totalmente "em casa", ou seja, se sintam "um pouco alienígenas". A divisão em "amigo ou inimigo", a que são frequentemente expostos os representantes de diferentes comunidades étnicas, é um dos problemas mais importantes associados à formação de uma identidade totalmente russa, e o estado real e o futuro das relações interétnicas no país dependem da solução dessa divisão.

Como enfatiza Popkov [2], "o fenômeno das diásporas modernas ainda contém um fenômeno pouco pesquisado de sobreposição de espaços sociais, étnicos e políticos, o que possibilitou o surgimento e a existência de enclaves étnicos globais que atravessam as fronteiras de culturas e estados".

Das definiçôes modernas do termo "diáspora", a mais significativa é a dos pesquisadores russos Toshchenko e Chaptykova: "a diáspora é um grupo estável de pessoas da mesma origem étnica, vivendo em um ambiente étnico estrangeiro fora de sua terra natal histórica (ou fora da área de circulação de seu próprio povo) e que tem instituiçōes sociais para o seu desenvolvimento e funcionamento como comunidade" [3].

As atividades das comunidades migrantes, os conflitos entre o país anfitrião e os migrantes, as questōes de redução das tensōes interétnicas e inter-religiosas, a possibilidade de integrar essas comunidades étnicas e, novamente, as possíveis adaptaçōes, são questōes que se tornaram agudas nos últimos anos para toda a comunidade mundial, incluindo e à frente de todos a Rússia. Nos últimos 50 anos, o número de migrantes internacionais mais que triplicou: em 1960 havia 75,5 milhōes de pessoas no mundo vivendo fora de seu país de nascimento; em 2000 já havia 174,5 milhōes de pessoas; e em seguida, até o final de 2013, 231,5 milhōes de pessoas. O seguinte quadro nos dá uma ideia mais detalhada desses números:

Metade de todos os migrantes internacionais, no entanto, vive em apenas dez países (dados de 2014):

1) Estados Unidos da América: 45,8 milhōes ou $20 \%$ do seu volume global;

2) Rússia: 11 milhões de pessoas

3) Alemanha: 9,8 milhões de pessoas

4) Arábia Saudita: 9,1 milhōes de pessoas

5) Emirados Árabes Unidos: 7,8 milhōes de pessoas

6) Grã-Bretanha: 7,8 milhōes de pessoas

7) França: 7,5 milhōes de pessoas 
Quadro 1. Volume de migração internacional (em milhões de pessoas)

\begin{tabular}{lllll}
\hline Ano & $\mathbf{1 9 9 0}$ & $\mathbf{2 0 0 0}$ & $\mathbf{2 0 1 0}$ & $\mathbf{2 0 1 3}$ \\
\hline Mundo & 154,2 & 174,5 & 220,7 & 231,5 \\
Regióes desenvolvidas & 82,3 & 103,4 & 129,7 & 135,5 \\
Regiōes em desenvolvimento & 71,9 & 71,1 & 91 & 95,9 \\
Átrica & 15,6 & 15,6 & 17.1 & 18,6 \\
Ásia & 49,9 & 50,4 & 67,8 & 70,8 \\
América Latina e Caribe & 7.1 & 6.5 & 8.1 & 8,5 \\
América do Norte & 27,8 & 40,4 & 51,2 & 53,1 \\
Europa & 49,0 & 56,2 & 69,2 & 72,4 \\
Oceania & 4,7 & 5,4 & 7,3 & 7,9 \\
\hline
\end{tabular}

Fonte: Departamento de Assuntos Econômicos e Sociais das Nações Unidas e OCDE [4]

8) Canadá: 7,3 milhões de pessoas

9) Austrália: 6,5 milhões de pessoas

10) Espanha: 6,5 milhões de pessoas

Assim sendo, estudar os problemas causados pelos desafios migratórios modernos enfrentados pela Rússia, em especial o surgimento de novas diásporas, impactando significativamente o cenário político nacional e estrangeiro, está se tornando cada vez mais atual. Se no início do surgimento e funcionamento da diáspora em um espaço cultural e político estrangeiro seus principais objetivos eram os de preservar a língua, tradições, costumes, cultura e a identidade etno-religiosa, nas últimas décadas as diásporas étnicas, tanto pela força de um aumento acentuado da identidade etno-religiosa, quanto por força de seus crescentes recursos econômicos, de informação e de organização política, começam a desempenhar um papel significativo na política interna e mesmo na política externa do país.

Aquestão dos aspectos etnolinguísticos (aspectos sociolinguísticos, culturais e linguísticos) do funcionamento das estruturas diaspóricas nas condições russas modernas é uma questão discutível e sem soluções óbvias. Por um lado, manter a lealdade linguística à comunidade étnica, reproduzir os fundamentos espirituais e culturais característicos do país de origem, manter as redes de comunicação com a pátria histórica e com os compatriotas — todas essas estão entre as preocupações mais importantes da diáspora. Por outro lado, a tendência à perda de competências linguísticas (especialmente em condições de migração para um local de residência permanente, os efeitos de fatores de aculturação de longo prazo, inclusive na perspectiva intergeracional) não bloqueia completamente o funcionamento das diásporas enquanto tal. A identidade etnocultural e etnolinguística pode ser suplementada e mantida na esfera da representação cotidiana, simbólica ou ritual.
No ambiente regulatório da diversidade cultural e do multilinguismo na Rússia moderna, as dimensões político-legais e sociocomunicativas da situação linguística e dos processos linguísticos de diferentes níveis (federal, regional, local) interagem de maneira contraditória. Estrategicamente declarados são os objetivos de preservar e desenvolver a diversidade etnocultural e as línguas dos povos da Rússia, princípios que não discriminam (direitos iguais são garantidos a todos, independentemente de raça, nacionalidade, idioma, origem, local de residência, religião ou outras circunstâncias). No entanto, a atitude de respeitar os direitos orientados à tolerância nem sempre é harmoniosamente combinada com o princípio de respeitar os direitos orientados à promoção (ou seja, institucionalizar ou reconhecer oficialmente os direitos do grupo de qualquer comunidade etnolinguística).

$\mathrm{O}$ assentamento de migrantes para residência permanente na Federação Russa —um recurso para aumentar a população e uma fonte de acumulação de capital humano - enfrenta um fator desfavorável: o baixo nível de conhecimento do idioma russo por migrantes de nova geração dos países da Comunidade dos Estados Independentes (CEI), devido a políticas linguísticas adotadas por esses países depois de 1991, com base na consolidação da posição dominante dos seus idiomas oficiais no sistema educacional e o enfraquecimento ou simples exclusão da língua russa. Nesse contexto, atitudes em relação à adaptação dos migrantes recém-chegados às exigências linguísticas e comunicacionais do mercado de trabalho e sua integração na comunidade anfitriã objetivamente entram em conflito com as atitudes em relação à satisfação dos interesses, demandas e necessidades dos migrantes em termos de reprodução de sua identidade etnocultural.

Os princípios fundamentais da política de migração estatal da Federação Russa priorizam as tarefas de ensino do idioma russo aos migrantes - o principal meio de inclusão (adaptação e integração dos migrantes), inclusive "criando a infraestrutura apropriada em seus países de origem, incluindo centros culturais e de adaptação" [5]. Além disso, uma das tarefas associadas à interação construtiva entre migrantes e a comunidade de acolhimento é criar uma "contra-exclusão social de migrantes, da segregação espacial e da formação de enclaves étnicos" [ibidem].

Ao mesmo tempo, os objetivos de aumentar a atratividade migratória da Federação Russa, a presença no país de trabalhadores temporários e outras categorias de imigrantes, bem como as obrigações humanitárias em relação aos migrantes forçados, exigirão, no futuro, expandir a infraestrutura de serviços linguísticos e fornecer bens públicos nas esferas de comunicação, bem como diversificar as políticas linguísticas das instituições de gestão e em especial dos departamentos relevantes responsáveis por trabalhar com migrantes.

Uma das áreas regulamentadas da política linguística é o sistema educacional. Essa área é caracterizada por tendências multidirecionais que ocorrem sob a influência de um conjunto complexo de fatores de natureza interna e externa, objetiva e subjetiva. De acor- 
do com dados oficiais de 2012, "277 línguas e dialetos são usados na Federação Russa, 89 idiomas são usados no sistema educacional estatal, 30 deles como línguas de instrução e 59 como objeto de ensino" [6]. Por si só, essa é uma conquista impressionante na implementação dos princípios do pluralismo na política linguística.

Em meados dos anos 2000, as línguas nativas "diaspóricas" (denominadas "sem título") também funcionavam no sistema educacional, tanto como meio de instrução quanto relacionadas com outras modalidades educacionais - azerbaijano, armênio, georgiano, cazaque, coreano, letão, lituano, alemão, grego moderno, polonês, turco, turcomano, ucraniano, finlandês, estoniano e chinês (com um número de alunos variável que vai de várias dezenas a vários milhares).

Por outro lado, em 2007 foram tomadas decisões para abolir os "componentes" nacional-regionais dos padrões educacionais, a fim de consolidar um único espaço educacional. Em 2008, foi adotada uma norma segundo a qual o Exame Unificado do Estado é realizado exclusivamente em russo. Objetivamente, essas medidas levam à redução da diversidade linguística no sistema educacional. No ano acadêmico de 2015/2016, a proporção de crianças que aprendem as línguas dos povos da Rússia (exceto russo) foi de: $1 \%$ como ferramenta de aprendizagem e $11 \%$ como disciplina. Entre as 26 línguas dos povos da Rússia, além da língua azerbaijana, as línguas "diaspóricas" (титульный язык, isto é, língua de etnia predominante em distrito, região, república etc.) não foram usadas como ferramenta de ensino.

Em agosto de 2018, foram adotadas emendas à lei "Sobre Educação", segundo a qual os alunos e os pais receberam o direito de escolher uma língua nativa para estudar, incluindo o idioma russo. O sistema de planejamento organizacional e metodológico da prática de estudar idiomas nativos ainda está no estágio inicial de design nas novas condições institucionais e regulatórias. O conceito de aprender idiomas nativos como documento identitário está em desenvolvimento.

É possível que em uma situação de migração em mudança (especialmente em megacidades, onde há um número significativo de migrantes em permanência constante), haja solicitaçôes para o estudo de línguas "diaspóricas" como idiomas nativos (dentro do escopo das oportunidades apresentadas pelo sistema educacional).

$\mathrm{Na}$ imprensa, por exemplo, foi relatado que o chefe do Comitê da Câmara Alta do Parlamento Tadjique para questóes sociais, ciência, educação e cultura, Forkhod Rakhim, pediu às autoridades russas que facilitassem o estabelecimento de uma escola em tadjique em Moscou. Cerca de 300.000 cidadãos e nativos do Tajiquistão vivem na capital e nos seus subúrbios. No entanto, autoridades russas observaram que "construir e abrir rapidamente escolas não funcionará", e que a decisão pode se dar em direção à abertura de escolas dominicais e à "criação de classes separadas" [7].

Aparentemente, os pré-requisitos normativos da lei russa "Sobre Autonomia Cultural Nacional" [8] podem ser considerados como a direção mais promissora na qual é possível ativar recursos para satis- fazer as necessidades e demandas culturais e linguísticas das comunidades e diásporas migrantes na Federação Russa. Nessa lei, foram desenvolvidas garantias constitucionais do direito dos cidadãos de preservar e desenvolver a língua nacional (nativa), e a liberdade de escolha e uso da língua de comunicação, educação e treinamento.

A lei prevê o direito de criar grupos e organizaçōes educacionais pré-escolares particulares, organizações educacionais gerais privadas e organizaçôes de ensino superior, cujo treinamento seja realizado na língua nacional (art. 11), como instituiçóes de autonomia cultural nacional (NKA). As autoridades estaduais e municipais, "levando em conta as propostas da NKA e as condições específicas da região, criam organizaçôes educacionais estaduais com treinamento na língua nacional (nativa), ou em russo, com estudo aprofundado da língua (nativa) nacional, história e cultura nacionais, além de informaçōes adicionais na educação (escolas dominicais, eletivas, centros culturais e educacionais e outras organizaçóes educacionais) para o estudo e promoção de línguas e culturas nacionais (nativas)" [9] (conforme versão alterada, que entrou em vigor em $1^{\circ}$ de setembro de 2013).

As diásporas étnicas estão alterando a estrutura demográfica, étnica e religiosa do país, às vezes começando a impor à sociedade anfitriã valores novos ou estranhos, o que pode aumentar os conflitos interétnicos e inter-confessionais. Ao mesmo tempo, existem outras abordagens relacionadas ao estudo dos problemas da migração e ao funcionamento das diásporas, não apenas na dimensão sociocultural. Antes de tudo, podemos observar um foco crescente nos estudos econômicos e demográficos da migração laboral.

Considerando a abordagem econômica e demográfica — arbitrariamente chamaremos assim - de forma alguma rejeitamos as disposiçōes e os princípios professados por seus partidários ou defensores. As tendências atuais no desenvolvimento econômico e demográfico de muitos dos principais países do mundo, incluindo a Rússia, expressas em uma redução de recursos de mão de obra e um decréscimo demográfico cada vez maior, nos fazem considerar a migração laboral como um fator no desenvolvimento econômico do país e como uma compensação pelo declínio vegetativo da população. Ao longo dos anos, desde o colapso da URSS, o crescimento da migração compensou amplamente mais da metade do declínio natural da população do país. No entanto, o tempo em que estamos vivendo nos faz olhar mais sobriamente e para outros aspectos dos problemas da migração e das comunidades diaspóricas.

Obviamente não há contradição entre as abordagens socioculturais e econômico-demográficas no estudo dos problemas da migração. Característico desse dualismo é o artigo de Ivakhnyuk [10], professor da Faculdade de Economia da Universidade Estatal de Moscou. Não questionamos as principais disposiçōes do artigo, que afirma que "no mundo moderno, a migração internacional da população, especialmente suas espécies e formas economicamente determinadas, é um importante recurso de desenvolvimento para os países anfitriōes e para os países de origem”. Além disso, as relações 
que surgem entre dois grupos de países por causa do movimento migratório são determinadas pelo autor como interdependência migratória. A conscientização da interdependência da migração estimula uma busca ativa de mecanismos que tornariam os fluxos migratórios mais dinâmicos e, assim, garantindo o uso efetivo do potencial de migração para os países receptores, para os países de destino e também para os próprios migrantes.

$\mathrm{O}$ artigo questiona o contexto alarmista do termo "dependência” nas disposições do trabalho de muitos pesquisadores. São defensores de uma visão muito alarmista dos problemas da migração, por exemplo, o pesquisador inglês $\mathrm{D}$. Coleman, autor do conceito da terceira transição demográfica, que traria mudanças étnicas irreversíveis para a população europeia; o político conservador americano P. Buchanan, que reclama, em seu livro com o característico título Morte do Ocidente, da já formada dependência do Ocidente do "doping imigratório" [11]; o pesquisador russo L L. Rybakovsky [12], que alertou a Rússia contra a "reavaliação irracional da possibilidade de uma variação demográfica aguda do desenvolvimento, em que a dinâmica populacional é completamente dependente do doping externo da migração, o que significaria "ficar apenas na dependência da migração", de acordo com o autor do artigo.

Na direção contrária está o professor A. G. Vishnevsky [13], que afirma que a imigração deve ser o fator chave no crescimento demográfico e econômico da Rússia e que representa, segundo o autor do artigo, uma abordagem mais equilibrada para esse problema. Nesse caso, consideramos os pontos de vista de Ivakhnyuk e Vishnevsky como os mais característicos e expressando, do nosso ponto de vista, as posições dos apoiadores de uma abordagem econômica e demográfica positiva para a migração.

Em nossa opinião, prevaleceu um ponto de vista semelhante no Conceito da Política de Migração da Federação Russa para o Período até 2025 , adotado em 13 de junho de 2012, no qual foram identificados os principais objetivos da política nacional de migração:

- "Estabilização e aumento da população residente da Federação Russa;

- Assistência para atender às necessidades da economia russa em mão de obra, modernização, desenvolvimento inovador e aumento da competitividade de suas indústrias."

No decreto do presidente da Federação Russa de 31 de outubro de 2018 "Sobre o Conceito de Política de Estado da Migração da Federação Russa para 2019-2025”, no entanto, houve um ajuste significativo na posição do Estado, observando que "a principal fonte de população da Federação Russa e do fornecimento de recursos de trabalho à economia nacional deve permanecer sendo a sua reprodução natural. A política de migração é uma linha auxiliar para resolver problemas demográficos e problemas econômicos relacionados".

No que tange ao desequilíbrio existente na distribuição da população no território da Federação Russa (na Sibéria e no Extremo
Oriente, que perfazem cerca de $2 / 3$ do território do país, vive apenas $8-10 \%$ da população), o problema do reassentamento ainda não foi resolvido. Levando em consideração o exterior, não há programas para atrair a residência permanente de migrantes com qualificaçôes profissionais demandadas pela economia e pelas características demográficas do país, estabelecendo pré-requisitos na área da educação e de perfis socioculturais, e na capacidade de se adaptar com sucesso e de se integrar à sociedade russa. As dificuldades em obter uma autorização de residência são um empecilho para a obtenção da cidadania para a maioria dos migrantes cumpridores da lei. Os mesmos objetivos descritos no Conceito de Política de Migração de Estado poderiam ser grandemente facilitados, resolvendo os problemas da migração interna, alterando o vetor da migração inter-regional do sul para o leste do país, removendo o ônus do desequilíbrio populacional do centro e da região de Moscou.

Eventos recentes, tanto na Europa como na Rússia, nos fazem adotar uma abordagem mais sóbria dos problemas do afluxo de migrantes, da formação de comunidades da diáspora e de conflitos cada vez mais frequentes entre migrantes e o país anfitrião. Mesmo os mais de três milhões da diáspora turca na Alemanha, em uma imigração que começou há mais de 50 anos, não podem ser considerados um exemplo de integração bem-sucedida na sociedade alemã. Na Alemanha, existem mais de 900 mesquitas e de acordo com estudos recentes, cerca de $15 \%$ dos turcos alemães podem ser considerados fundamentalistas; um em cada três turcos na Alemanha (mais de um milhão de pessoas) consideraria possível construir uma sociedade baseada nos princípios dos tempos do profeta Maomé [14].

O professor alemão Gunnar Heinzon, que previu uma "grande migração de povos" no início do século XXI, alerta para o perigo de africanos e árabes dominarem a Europa em meados do século XXI [15]. A ex-primeira-ministra britânica Theresa May disse que o país precisa reduzir a frequência da migração anual para "dezenas de milhares" de pessoas, relata a Reuters. Segundo ela, o governo britânico sempre procurou reduzir a migração para o Reino Unido e levá-la a um nível "estável”: "Acredito que o nível estável é de dezenas de milhares de visitantes", disse May. Em junho de 2016, o ex-primeiroministro britânico David Cameron disse: "Precisamos interromper os fluxos migratórios para que eles não cheguem ao Reino Unido" [16]. Existem muitos fatos e relatórios que testemunham mudanças sérias na política de migração na direção de um maior fechamento.

A falta de uma análise abrangente de todas as possíveis consequências do contato de pessoas de diferentes tradições, culturas, costumes e visões de mundo em uma sociedade, a falta de uma experiência secular de cidadania conjunta de pessoas com uma grande distância cultural, de uma política de tolerância geral e total sem levar em conta as especificidades étnicas, tradicionais e culturais, teriam levado às consequências que observamos na Europa, ou ouvimos pela boca de vários líderes dos principais países da europeus - Alemanha, França e Reino Unido — de que a política do multiculturalismo na Europa teria falhado. 
Cada vez mais grupos étnicos se encontram fora dos sistemas de coordenadas dos Estados e da ordem mundial, bem como das abordagens e práticas tradicionais consolidadas estabelecidas nos países. A maioria das novas diásporas enfrenta os mesmos problemas informacionais, de comunicação, políticos, culturais, integração e adaptação no seu novo ambiente.

As diásporas geralmente podem ter um impacto significativo nos processos de política doméstica e externa do país de residência. Outra característica dessas diásporas é que elas podem ter um impacto significativo nos "países de origem". Para coordenar esse trabalho, são criados ministérios e departamentos especiais. Como exemplo, pegamos as diásporas étnicas de três países que têm informaçôes disponíveis em fontes abertas nos sites do governo.

O Ministério da Diáspora da República da Armênia, por exemplo, "desenvolve e implementa programas classificados de pan-armênios para o desenvolvimento da parceria Armênia-Diáspora, fortalecendo a avaliação da Armênia nesse campo, e é projetado para contribuir para a preservação, a proteção, o desenvolvimento e a disseminação do patrimônio cultural da Armênia, e para contribuir com os esforços da Armênia pelo reconhecimento do genocídio armênio pelos Estados e pela comunidade internacional" [17].

O Ministério da Diáspora e Informação de Israel é responsável "pelas relaçōes do Estado de Israel com a Diáspora Judaica e por explicar as políticas israelenses na arena internacional. O Ministério inclui a Empresa Estatal de Publicidade e a Administração Estatal de Jornalismo e o Ministério da Diáspora e Informação que trabalham em estreita colaboração com embaixadas e consulados de Israel em todo o mundo e com o Escritório de Informação e Diáspora (תוצופתהו הרבסההדרשמ).

A Agência Estatal da Geórgia para Assuntos da Diáspora (com estatuto de ministério) é responsável "por estabelecer e manter contatos com a diáspora da Geórgia no exterior” [18]. Sem dúvida, qualquer Estado deve defender, antes de tudo, seus interesses nacionais.

Muitos pesquisadores dos problemas das diásporas étnicas enfatizam a capacidade dessas diásporas de preservar sua identidade étnico-religiosa e a solidariedade comunitária, de fortalecer contatos constantes com organizações e estruturas do "país de origem" e do país de residência. Frequentemente, observamos uma situação em que as diásporas étnicas tentam participar ativamente e influenciar as posições de política interna e externa do país anfitrião. Exemplos de tais tentativas são vistos, no primeiro caso, no apelo da diáspora do Azerbaijão ao presidente da Duma, a Câmara Baixa da Assembleia Federal da Rússia, S.E. Naryshkin, sobre o projeto de lei que criminaliza a negação do "genocídio armênio". O apelo foi assinado por todos os chefes das filiais regionais russas da diáspora do Azerbaijão, liderados por A. Maharramov, membro do Conselho de Relações Interétnicas da Presidência da Rússia, e disse que "nós, cidadãos da Rússia, por nossa parte, continuaremos a negar publicamente o 'genocídio armênio', mesmo no caso de adoção de tal emenda”, o que pode ser considerado uma tentativa de pressionar o poder legislativo.
No segundo caso, isso foi observado após a chamada "Guerra dos Quatro Dias” em Nagorno-Karabakh, quando a diáspora armênia exigiu ativamente que o governo russo parasse de fornecer armas russas ao Azerbaijão. Também observamos tentativas da diáspora tadjique de usar o fato da Base Militar 201ª da Rússia localizar-se no Tajiquistão para obter preferências para migrantes tadjiques, às vezes com algum sucesso.

Podemos citar um número suficiente desses exemplos em cada uma das grandes diásporas, mas a essência da questão não muda até que ponto o Estado pode ir no sentido de fortalecer o papel das diásporas étnicas? Isso não ameaçará, de fato, os interesses nacionais do país? Naturalmente, a Rússia, sendo a maior potência regional e o principal membro de organizaçôes internacionais - como a Comunidade dos Estados Independentes (CEI), a União Econômica Eurasiática (EAEU), a Organização do Tratado de Segurança Coletiva, a União Aduaneira - está interessada em fortalecer seu papel na integração da Eurásia, o que exige que o país tenha uma atitude extremamente delicada e equilibrada em relação aos problemas de migração e diásporas étnicas.

A migração, especialmente ilegal, como vemos nos países da União Europeia (UE) e na Rússia, carrega um grande número de ameaças à própria existência dos Estados. Vimos que a política de migração dos países europeus levou ao fato de que líderes dos principais centros de poder - Alemanha, Grä-Bretanha e França - foram forçados a admitir que a política do multiculturalismo falhou. Mas esse fato não levou a uma mudança significativa nas abordagens dos líderes europeus ao problema, o que, por sua vez, levou a discordâncias entre os membros da UE.

Estamos testemunhando uma situação na Europa em que a distância cultural entre refugiados e a sociedade anfitriã é muito grande, resultando em numerosos casos de comportamentos problemáticos por parte dos refugiados. $\mathrm{Na}$ verdade, decisões políticas tomadas sem análise adequada e previsão das possíveis consequências de receber um número tão grande de migrantes levaram a uma situação em que sentimentos antimigrantes estão começando a surgir na sociedade, muitas vezes levando à violência entre os próprios migrantes.

$\mathrm{Na}$ França, onde a porcentagem de migrantes em relação à população local se aproxima de $15 \%$, observamos que a política de migração das autoridades não levou à integração de migrantes nas comunidades locais, não levou à sua adaptação às regras e regulamentos locais, em uma situação em que os migrantes geralmente não querem aceitar valores do local de acolhimento. Inicialmente, a política de estabelecer migrantes em "guetos" sociais fora das grandes cidades levou ao fato de que nos enclaves étnicos formados não há motivação para integrar e adaptar-se às condições, regras e tradiçôes locais. A atual situação alarmante de migração na Europa levou ao aumento esperado da popularidade dos partidos de direita nos países da UE, ao aumento de sentimentos anti-migrantes e, às vezes, à violência contra migrantes. 
Pela primeira vez, a chanceler alemã Angela Merkel, que iniciou a política de portas abertas para refugiados, admitiu que também terroristas entraram na Europa com os migrantes. Nesse sentido, devemos prestar mais atenção aos problemas da migração, aos conflitos emergentes e possíveis ligados aos modos possíveis da sua participação nas sociedades.

É preciso admitir, entretanto, que a experiência russa secular da coexistência de diferentes crenças, culturas e tradições e, na verdade, a moderna política de migração estatal russa, essencialmente - e para melhor - a distingue da experiência europeia. Os documentos fundamentais do planejamento estratégico do Estado no campo das relações interétnicas e a política de migração do Estado explicitam claramente as prioridades, metas, princípios, mecanismos e principais diretrizes atuais para a implementação da política nacional e da política de migração do Estado.

Em um país multinacional como a Rússia (de acordo com o Censo de 2010, viviam no país representantes de 193 nacionalidades), e que ocupa o segundo lugar no mundo em número de migrantes legais e ilegais, atenção especial e extremamente ampliada deve ser dada ao estado das relações interétnicas e à situação da migração.

Os processos de migração desempenham, conforme prescrito no Conceito citado, um papel significativo no desenvolvimento econômico e demográfico do país. Enfatiza-se no documento que a criação de condições para a adaptação e a integração dos migrantes, protegendo seus direitos e liberdades, garantindo sua segurança social são elementos importantes da política de migração do Estado. A esse respeito, gostaria de enfatizar que, no Conceito de Política Externa da Rússia, o desenvolvimento da cooperação bilateral e multilateral com os Estados membros da CEI é uma área prioritária da política externa da Rússia.

Analisando os fatores acima, parece que a necessidade de uma política de migração equilibrada e eficaz está aumentando. A difícil situação geopolítica, econômica e política prevalecente no mundo e na Rússia nos leva a adotar uma abordagem equilibrada dos problemas identificados. Os problemas e desafios da migração que abalaram a unidade política da UE devem ser resolvidos na Rússia à luz da experiência russa positiva e das especificidades do país.

Dada a experiência de viver juntos em um grande país a União das Repúblicas Socialistas Soviéticas (URSS) —, uma longa história conjunta, a formação de muitos valores comuns, apesar da diferença de tradições e culturas, a Rússia é capaz de evitar as dificuldades e os problemas causados pelo influxo de grandes comunidades étnicas, muitas das quais transformadas em influentes etnias nas diásporas. É necessário adotar políticas claras tanto com diásporas existentes como com as emergentes, mas sempre em consonância, em primeiro lugar, com a defesa dos interesses nacionais russos.

Magomed A. Omarovédoutor em ciência política, diretor do Centro de Pesquisa e Ensino em Estudos Etnopoliticos da Universidade Estatal Russa para as Humanidades (RGGU), Moscou, Federação Russa.

\section{REFERÊNCIAS}

1. Brubaker, R. “Diásporas do cataclismo na Europa Central e Oriental e suas relações com suas pátrias (por exemplo, Alemanha de Weimar e Rússia pós-soviética)". Diásporas, nº. 3, 2000.

2. Popkov, V. D. O fenômeno das diásporas étnicas. Moscou, 2003.

3. Toshchenko, Zh.T.; Chaptykova, T.I. "Diáspora como objeto de pesquisa sociológica". Socis. M., nº.12, 1996.

4. Disponível em: https://www.oecd.org/els/mig/PORTUGUESE.pdf

5. Decreto do presidente da Federação Russa de 31.10.2018, no. 622 "Sobre o conceito de política de migração estatal da Federação da Rússia para 2019-2025"

6. Decreto do presidente da Federação Russa de 19 de dezembro de 2012, nº 1666 (emendado em 6 de dezembro de 2018) "Sobre a estratégia da política nacional do estado da Federação da Rússia para o período até $2025 "$.

7. AiF, 20 de outubro, 2018

8. Lei n. 74-F3, aprovada pelo presidente, 17 de junho de 1996.

9. Lei Federal de 2 de julho de $2013, n^{0}$. 185-FZ

10. Ivakhnyuk, I. V. "Migração internacional de mão de obra", 2005. Disponível em: http://www.socionauki.ru/journal/articles/132578/

11. Buchanan P. J. Morte do Ocidente: como a extinção da população e o aumento da imigração ameaçam nosso país e nossa civilização. Editora AST, 2003.

12. Rybakovsky L.L. "O futuro demográfico da Rússia e os processos de migração". Demografia, Migrações, 2005.

13. Vishnevsky A.G. "O futuro demográfico da Rússia”. Notas domésticas, n०. 4, 2004.

14. "Turcos na Alemanha - o mito da integração bem-sucedida", 2016. Disponível em: https://regnum.ru/news/polit/2160328.html

15. "Quantos africanos correm para a Europa", 2016. Disponível em: http://newrezume.org/news/2016-01-16-12703

16. Disponível em: http://www.gazeta.ru/social/news/2016/07/20/ n_8904071.shtml

17. Disponível em: http://www.mindiaspora.am/en/index

18. Disponível em: http://diaspora.gov.ge/ 